\title{
PENGARUH IMPLEMENTASI PRINSIP-PRINSIP GOOD CORPORATE GOVERNANCE TERHADAP KINERJA MANAJERIAL PADA BANK PEMBANGUNAN DAERAH (BPD) DAERAH ISTIMEWA YOGYAKARTA
}

\author{
Nur Hidayah \\ Alia Ariesanti
}

\begin{abstract}
Implementation of good corporate governance in banks is expected to eliminate mismanagement, forming a system of checks and balances that guarantee effective and all-powerful corporation in line with improving corporate performance through the creation process of making better decisions, improve operational efficiency and further improve services to stakeholders. The study was conducted to provide empirical evidence of the influence of the implementation of good corporate governance on managerial performance in Yogyakarta BPD Bank. Research object is the middle and lower level managers in the Regional Development Bank (BPD) Special Region of Yogyakarta. The data used are the primary data from respondents' answers, the manager at the Bank BPD DIY. This study uses multiple linear regression analysis. The results showed that: (1) Transparency affect managerial performance. (2) Accountability affect managerial performance. (3) Responsibility affect managerial performance. (4) independency affect managerial performance. (5) Fairness does not affect managerial performance.
\end{abstract}

Keywords: Good Corporate Governance (Transparency, Accountability, Responsibility, Inpendency, Fairness), Managerial Performance

\section{PENDAHULUAN}

Penerapan good corporate governance (GCG) sangat dibutuhkan dalam bisnis perbankan. Kinerja suatu bank sangat erat hubungannya dengan peran dan fungsi manajemen dari bank tersebut dalam pengelolaan bank. Penerapan GCG di dalam perbankan diharapkan dapat berpengaruh terhadap kinerja perbankan, dikarenakan penerapan corporate governance ini dapat meningkatkan kinerja keuangan dan mengurangi risiko akibat tindakan pengelolaan yang cenderung menguntungkan diri sendiri.

Seiring dengan tuntutan penerapan GCG pada sektor perbankan, maka pada tahun 2006 Bank Indonesia menggagas peraturan yang secara khusus mengatur mengenai ketentuan pelaksanaan GCG di Bank Umum. Peraturan yang dimaksud adalah Peraturan Bank Indonesia Nomor 8/4/PBI/2006 tanggal 30 Januari 2006 tentang Pelaksanaan GCG bagi Bank Umum yang kembali disempurnakan melalui 
PBI Nomor 8/14/PBI/2006 tanggal 5 Oktober 2006 tentang Perubahan atas PBI Nomor 8/4/PBI/2006 tentang Pelaksanaan Good Corporate Governance bagi Bank. Motivasi penelitian ini adalah ingin mengetahui pengaruh implementasi prinsipprinsip GCG terhadap kinerja manajerial pada Bank Pembangunan Daerah (BPD) Daerah Istimewa Yogyakarta.

\section{LANDASAN TEORI DAN PENGEMBANGAN HIPOTESIS}

\section{Pengaruh Good Corporate Governance terhadap Kinerja Manajerial}

Pada dasarnya isu tentang corporate governance dilatar belakangi oleh agency theory yang menyatakan permasalahan agency muncul ketika pengelolaan suatu perusahaan terpisah dari kepemilikannya. Dengan penerapan GCG pada perbankan diharapkan dapat meningkatkan kinerja perusahaan, mengurangi risiko yang mungkin dilakukan oleh dewan dengan keputusan yang menguntungkan sendiri dan umumnya GCG dapat meningkatkan kepercayaan investor untuk menanamkan modalnya yang berdampak terhadap kinerjanya. Berdasar penjelasan tersebut, maka dirumuskan hipotesis sebagai berikut:

$\mathrm{H}_{1}$ : Transparency berpengaruh terhadap kinerja manajerial.

$\mathrm{H}_{2}$ : Accountability berpengaruh terhadap kinerja manajerial.

$\mathrm{H}_{3}$ : Responsibility berpengaruh terhadap kinerja manajerial

$\mathrm{H}_{4}$ : Independency berpengaruh terhadap kinerja manajerial.

$\mathrm{H}_{5}$ : Fairness berpengaruh terhadap kinerja manajerial.

\section{METODA PENELITIAN}

\section{Objek Penelitian}

Objek penelitian adalah manajer level atas, menengah dan bawah pada Bank Pembangunan Daerah (BPD) Daerah Istimewa Yogyakarta.

\section{Jenis dan Sumber Data}

Jenis dan sumber data menggunakan data primer yang berasal dari jawaban responden, yaitu manajer di Bank BPD DIY.

\section{Teknik Pengumpulan Data}

Penelitian ini dilakukan dengan cara menyerahkan langsung kuesioner dan meminta kembali pada tanggal yang dijanjikan oleh responden. 


\section{Operasional dan Pengukuran Variabel}

Variabel Independen: Good corporate governance (transparency, accountability, responsibility, indepency, fairness).

Variabel Dependen: Kinerja manajerial.

\section{HASIL PENELITIAN DAN PEMBAHASAN}

\section{Deskripsi Objek Penelitian}

Objek pada penelitian ini adalah manajer Bank BPD DIY yang disebarkan ke 4 Kabupaten dan 1 Kotamadya di Daerah Istimewa Yogyakarta. Untuk mengetahui implementasi good coorporate governance dan kinerja manajerial pada Bank BPD DIY, peneliti menyebar 60 kuisioner dan kembali 55 kuisioner, sehingga tingkat pengembalian adalah 91\%. Responden pada penelitian ini adalah 22 orang manajer tingkat menengah (40\%) dan 33 orang manajer tingkat bawah $(60 \%)$ pada Bank BPD DIY yang memiliki rata-rata masa kerja pada jabatan sekarang sekitar 2 tahun dan rata-rata masa kerja di Bank BPD DIY sekitar 20 tahun. Manajer tingkat menengah yang berpendidikan S2 adalah 20 orang, yang berpendidikan S1 adalah 2 orang. Untuk manajer tingkat bawah yang berpendidikan S2 adalah 4 orang, dan yang berpendidikan S1 adalah 29 orang.

\section{Hasil Analisis Data}

\section{Hasil Uji Validitas dan Reliabilitas}

Hasil pengujian validitas masing-masing bulir pada setiap variable menunjukkan bahwa nilai corrected item-total correlation menunjukkan lebih besar dari 0,3. Sehingga butir yang digunakan tersebut valid. Dengan demikian seluruh pertanyaan yang ada pada instrumen penelitian tersebut layak digunakan sebagai kuesioner.

Hasil pengujian reliabilitas pada setiap variabel menunjukkan bahwa nilai Cronbach's Alpha lebih besar dari 0,6. Sehingga bulir pertanyaan yang digunakan variabel tersebut reliabel. Dengan demikian seluruh pertanyaan yang ada pada instrumen penelitian masing-masing variabel tersebut layak digunakan sebagai kuisioner. 


\section{Hasil Uji Asumsi Klasik}

\section{a. Uji Normalitas}

Pengujian normalitas menggunakan uji Kolmogorov-Smirnov. Hasil uji normalitas menunjukkan nilai signifikansi Kolmogorov-Smirnov yaitu 0,423 > 0,05, hal ini berarti data residual terdistribusi normal.

\section{b. Uji Multikolinieritas}

Hasil uji multikolinieritas menunjukkan bahwa pada perhitungan VIF tidak ada satu variabel indepen den yang memiliki nilai VIF lebih dari 10. Berdasar hasil tersebut, dapat diketahui bahwa tidak ada multikolinieritas.

\section{c. Uji Heteroskedastisitas}

Hasil uji glejser menunjukkan nilai signifikansi masing-masing variabel independen di atas 0,05. Berdasar hasil tersebut, dapat diketahui bahwa tidak terjadi heteroskedastisitas.

\section{d. Uji Autokolerasi}

Nilai DW sebesar 2,154 nilai ini akan dibandingkan dengan nilai tabel dengan menggunakan signifikansi 5\% untuk jumlah sampel $\mathrm{n}=55, \mathrm{k}=5$ nilai $\mathrm{dl}=1,374$ dan $\mathrm{du}=1,768$. Oleh karena nilai $\mathrm{DW}>1,374$, maka dapat disimpulkan bahwa tidak terdapat autokorelasi.

\section{Hasil Analisis Regresi}

\section{a. Hasil Uji Koefisien Determinan}

Nilai Adjusted R Square sebesar 0,789\%. Nilai ini menerangkan besarnya peran atau kontribusi variabel independen yang mampu menjelaskan variabel dependen sebesar $78,9 \%$. Sedangkan sisanya sebesar $21,1 \%$ dijelaskan oleh faktorfaktor lain di luar model yang dianalisis.

\section{b. Uji Statistik F}

Nilai $\mathrm{F}$ dalam regresi menunjukkan pengaruh variabel independen terhadap variabel dependen. Regresi total memiliki F hitung sebesar 41,351 dengan signifikansi 0,000 yang menunjukkan bahwa nilai signifikansi tersebut $<0,05$ berarti minimal terdapat salah satu variabel independen yang berpengaruh terhadap variabel dependen. 


\section{c. Uji Statistik t}

Nilai t ( $\mathrm{t}$ hitung) dalam regresi menunjukkan pengaruh variabel independen terhadap variabel dependen. Transparency memiliki t hitung sebesar 2,217 dengan signifikansi 0,031 , berarti terdapat pengaruh transparency terhadap kinerja manajerial. Accountability memiliki t hitung sebesar 3,433 dengan signifikansi 0,001, berarti terdapat pengaruh accountability terhadap kinerja manajerial. Responsibility memiliki t hitung sebesar 3,653 dengan signifikansi 0,001, berarti terdapat pengaruh responsibility terhadap kinerja manajerial. Independency memiliki t hitung sebesar 5,630 dengan signifikansi 0,000, berarti terdapat pengaruh independency terhadap kinerja manajerial. Fairness memiliki t hitung sebesar 1,659 dengan signifikansi 0,103, berarti tidak terdapat pengaruh fairness terhadap kinerja manajerial.

\section{PEMBAHASAN}

Berdasar hasil pengujian yang telah dilakukan, ditemukan beberapa hasil penelitian. Hasil penelitian tersebut menunjukkan bahwa transparency berpengaruh terhadap kinerja manajerial, accountability berpengaruh terhadap kinerja manjerial, responsibility berpengaruh terhadap kinerja manajerial, independency berpengaruh terhadap kinerja manajerial, fairness tidak berpengaruh terhadap kinerja manajerial dan secara parsial good corporate governance berpengaruh terhadap kinerja manajerial pada Bank BPD DIY.

\section{Pengaruh Transparency terhadap Kinerja Manajerial}

Hasil pengujian diketahui bahwa transparency mempengaruhi kinerja manajerial. Hal ini memberikan bukti empiris bahwa mekanisme pemantauan pengungkapan melalui auditor eksternal berpengaruh signifikan terhadap kinerja perbankan. Hal tersebut akan mendorong manajemen untuk meningkatkan kinerja manajerial. Hasil ini mendukung penelitian Sari (2010) bahwa mekanisme pemantauan pengungkapan melalui auditor eksternal berpengaruh signifikan terhadap kinerja perbankan

\section{Pengaruh Accountability terhadap Kinerja Manajerial}

Hasil pengujian diketahui bahwa accountability mempengaruhi kinerja 
manajerial, hasil ini mendukung penelitian Sari (2010). Hal ini memberikan bukti empiris bahwa ukuran dewan direksi berpengaruh terhadap kinerja perbankan. Dengan adanya kejelasan fungsi, pelaksanaan dan pertanggungjawaban organ organisasi maka pengelolaan bank terlaksana secara efektif. Dengan memiliki ukuran kinerja dari semua jajaran bank berdasarkan ukuran-ukuran yang disepakati konsisten dengan nilai perusahaan, sasaran usaha dan strategi bank serta memiliki reward and punishment system maka akan berpengaruh terhadap kinerja manajerial.

\section{Pengaruh Responsibility terhadap Kinerja Manajerial}

Hasil pengujian diketahui bahwa responsibility mempengaruhi kinerja manajerial, hasil ini mendukung penelitian Muwarningsari (2009). Hal ini memberikan bukti empiris bahwa corporate social responsibility berpengaruh signifikan terhadap kinerja perusahaan. Dengan mematuhi hukum dan peraturan serta memenuhi tanggungjawaban yang terhadap masyarakat dan lingkungan akan mampu menjaga kesinambungan perusahaan jangka panjang.

\section{Pengaruh Independency terhadap Kinerja Manajerial}

Hasil pengujian diketahui bahwa independency mempengaruhi kinerja manajerial, hasil ini mendukung penelitian Maryanah dan Amilin (2011) menyatakan bahwa dari hasil uji hipotesis diketahui bahwa independency Dewan Komisaris berpengaruh positif terhadap kinerja perusahaan. Dengan pengelolaan secara profesional tanpa benturan kepentingan dan pengaruh atau tekanan dari pihak manapun, manajemen mampu melaksanakan fungsi dan tugasnya sesuai dalam anggaran dasar dan peraturan sehingga pengambilan keputusan dilakukan secara objektif.

\section{Pengaruh Fairness terhadap Kinerja Manajerial}

Hasil pengujian diketahui bahwa fairness tidak mempengaruhi kinerja manajerial, hasil ini mendukung penelitian Sari (2009). Hal ini memberikan bukti empiris bahwa mekanisme pemantauan kepemilikan menunjukkan pengaruh yang tidak signifikan terhadap kinerja perbankan. Hasil pengujian ini juga didukung oleh penelitian yang dilakukan Wulandari (2006) yang memberikan bukti empiris bahwa institutional ownership atau kepemilikan institusional berpengaruh terhadap kinerja. Hasil penelitian ini menunjukkan bahwa pemilik mayoritas institusi ikut 
dalam pengendalian perusahaan sehingga cenderung bertindak untuk kepentingan mereka sendiri meskipun dengan mengorbankan kepentingan pemilik minoritas.

Dengan adanya kecenderungan tersebut membuat terjadinya ketidakseimbangan dalam penentuan arah kebijakan perusahaan. Artinya pada variabel fairness, seharusnya manajemen mampu memberikan peluang bagi para pemangku kepentingan untuk memberikan masukan dan menyampaikan pendapat bagi kepentingan organisasi sesuai dengan prinsip transparansi dan dalam kapasitasnya masing-masing, serta mempertimbangkan kepentingan pemegang saham dan pemangku kepentingan lainnya berdasarkan asas keadilan. Namun pada kenyataannya hal ini tidak didukung oleh adanya perbedaan kepentingan dari masing-masing pemegang saham. Berdasarkan penelitian sebelumnya telah ditemukan bahwa pemegang saham mayoritas memiliki peluang dan perhatian yang lebih besar dalam menyampaikan pendapatnya sehingga hal ini akan mempengaruhi pengambilan keputusan manajemen. Hal ini memberikan bukti empiris bahwa fairness tidak berpengaruh terhadap kinerja manajerial.

\section{SIMPULAN, KETERBATASAN, DAN SARAN}

Berdasar hasil pengujian dan pembahasan mengenai pengaruh variabel transparency, accountability, responsibility, independency dan fairness terhadap kinerja manajerial, maka peneliti dapat meringkas penemuan pada penelitian ini adalah sebagai berikut:

1. Hasil pengujian hipotesis pertama menunjukkan transparency berpengaruh terhadap kinerja manajerialada Bank Pembangunan Daerah (BPD) Daerah Istimewa Yogyakarta.

2. Hasil pengujian hipotesis kedua menunjukkan accountability berpengaruh terhadap kinerja manajerial pada Bank Pembangunan Daerah (BPD) Daerah Istimewa Yogyakarta.

3. Hasil pengujian hipotesis ketiga menunjukkan responsibility berpengaruh terhadap kinerja manajerial pada Bank Pembangunan Daerah (BPD) Daerah Istimewa Yogyakarta.

4. Hasil pengujian hipotesis keempat menunjukkan independency berpengaruh 
terhadap kinerja manajerial pada Bank Pembangunan Daerah (BPD) Daerah Istimewa Yogyakarta.

5. Hasil pengujian hipotesis kelima menunjukkan fairness tidak berpengaruh terhadap kinerja manajerial pada Bank Pembangunan Daerah (BPD) Daerah Istimewa Yogyakarta.

Penelitian ini mempunyai keterbatasan-keterbatasan yang dapat dijadikan bahan pertimbangan bagi peneliti berikutnya agar mendapatkan hasil yang lebih baik lagi.

1. Penelitian ini menerapkan metoda survei menggunakan kuesioner tanpa dilengkapi dengan wawancara atau pertanyaan lisan, sehingga peneliti tidak dapat mengontrol jawaban responden yang bisa jadi bukan jawaban sebenarnya.

2. Responden terbatasi hanya pada setingkat manajer level menengah dan bawah, yaitu manajer di kantor-kantor cabang DIY sehingga hasil penelitian ini tidak dapat digeneralisir

Berdasar hasil analisis pembahasan serta beberapa kesimpulan dan keterbatasan pada penelitian ini, adapun saran-saran yang dapat diberikan melalui hasil penelitian ini agar mendapatkan hasil yang lebih baik, yaitu:

1. Untuk penelitian berikutnya dilengkapi dengan wawancara atau pertanyaan lisan agar peneliti dapat mengontrol jawaban responden yang bisa jadi bukan jawaban sebenarnya.

2. Untuk penelitian berikutnya responden dilengkapi dengan penelitian pada manajer level atas, manajer level menengah dan bawah, sehingga hasil penelitian ini dapat digeneralisir.

\section{DAFTAR PUSTAKA}

Arafat, Wilson. 2010. Good Corporate Governance: Pedoman Komprehensif Mengukur Kinerja Penerapan GCG. Yogyakarta: Andi Jogjakarta .

Aditya Fitri Siregar dan Erlina. 2009. Pengaruh Pengetahuan Akuntansi dan Kepribadian Wirausaha terhadap Kinerja Manajerial pada Perusahaan Jasa di Kota Medan. Skripsi. Universitas Sumatera Utara.

Azhar, Nelda, 2008. Uji Validitas dan Reliabilitas Paket Multimedia Interaktif. 
[Online].Didapatkan: http://elektronika.unp.ac.id [30Januari 2012]

Ghozali, Imam. 2001. Aplikasi Analisis Multivariate dengan Program SPSS. Semarang: Penerbit Universitas Diponegoro.

Gravatar, 2010, Uji Validitas dan Reliabilitas [Online]. Didapatkan: http://teorionline.wordpress.com [30 Januari 2012]

Leo, J Susilo dan Karlen Simarta. 2007. Good Corporate Governance pada Bank . Tanggungjawab Direksi \& Komisaris dalam Melaksanakannya. Jakarta: PT Hikayat Dunia.

Martono dan Agus Harjito. 2005. Manajemen Keuangan. Yogyakarta: Ekonisia Kampus Fakultas Ekonomi UII.

Muwarningsari, Etty. 2009. "Hubungan Corporate Governance, Corporate Social Responsibility dan Corporate Financial Performance dalam Satu Continum”. Jurnal Akuntansi dan Keuangan, Vol.11, No.1, Mei 2009:3041.

Maryanah dan Amilin. 2011. Pengaruh Corporate Governance dan Kepemilikan Manajerial terhadap kinerja Perusahaan (Studi pada Perusahaan yang Terdaftar di Bursa Efek Jakarta). Jakarta: Universitas Islam Negeri Syarif Hidayatullah.

Pedoman Good Corporate Governance Perbankan Indonesia (2004) yang dikeluarkan Komite Nasional Kebijakan Corporate Governance (KNKG). Didapatkan: http:www.governance_indonesia.com [23 Februari 2011].

Peraturan Bank Indonesia Nomor 8/4/PBI/2006 Tentang Pelaksanaan Good Corporate Governance Bagi Bank Umum.

Pratiwi, Dhika. 2008. Analisis Pengukuran Kinerja Perusahaan Dengan Konsep Balance Scorecard (Studi Kasus Pada PT Bank Tabungan Negara (Persero) Cabang Solo). Skripsi. Universitas Muhammadiyah Surakarta.

Ristifani. 2009. Analisis Implementasi Prinsip-Prinsip Good Corporate Governance (GCG) dan Hubungannya Terhadap Kinerja PT. Bank Rakyat Indonesia (Persero) Tbk. Skripsi. Universitas Gunadarma.

Sari, Irmala. 2010. Pengaruh Mekanisme Good Corporate Governance terhadap 
Kinerja Perbankan Nasional (Studi pada Perusahaan Perbankan yang Terdaftar di Bursa Efek Indonesia Periode 2006-2008). Skripsi. Universitas Diponegoro Semarang.

Wardani, Kusuma. 2008. Pengaruh Corporate Governance terhadap Kinerja Perusahaan di Indonesia. Skripsi. Universitas Islam Indonesia Yogyakarta.

Wijaya, Krisna. 2002. Reformasi Perbankan Nasional . Jakarta: Harian Kompas.

Wulandari, Ndaruningpuri. 2006. "Pengaruh Indikator Mekanisme Corporate Governance terhadap Kinerja Perusahaan Publik di Indonesia". Jurnal Ekonomi (Januari), hal. 120-135.

http://www.bankirnews.com/

http://www.bi.go.id/web/id/perbankan+arsitektilur+perbankan+Indonesia/.

Yulianasari, Nina. 2009. Pengaruh Kejelasan Sasaran Anggaran dan Sistem Pengendalian Akuntansi Terhadap Kinerja Manajerial (Studi pada Pemerintah Daerah Kabupaten Cirebon). Skripsi. Universitas Ahmad Dahlan Yogyakarta. 